\title{
Florid Endocervical Microglandular Hyperplasia in Association with Tamoxifen Treatment
}

\author{
Ayakannu $\mathrm{T}^{1}$, Hew WSR ${ }^{2}$, Brown $\mathrm{L}^{2}$, Ismail S ${ }^{3}$, Maulik TG ${ }^{4}, \mathrm{Kiberu}_{\mathrm{SW}}$ and Taylor $\mathrm{AH}^{1,5^{*}}$ \\ ${ }^{1}$ Reproductive Sciences Section, Department of Cancer Studies and Molecular Medicine, University of Leicester, Leicester, UK \\ 2 University Hospitals of Leicester NHS Trust, Pathology Department, Leicester, UK \\ ${ }^{3}$ University Hospital of South Manchester NHS Foundation Trust, M23 9LT, UK \\ ${ }^{4}$ Department of Obstetrics and Gynaecology, Prince Charles Hospital, Merthyr Tydfil, South Wales, CF47 9DT, UK \\ ${ }^{5}$ Biosciences, School of Science and Technology, Nottingham Trent University, Clifton Campus, Nottinghamshire, UK \\ *Corresponding author: Anthony H Taylor, Biosciences, School of Science and Technology, Nottingham Trent University, Clifton Campus, Nottinghamshire, UK, Tel: \\ +44 01158485322; E-mail: superdoc.at@gmail.com
}

Received date: Aug 04, 2015, Accepted date: Oct 13, 2015; Published date: Oct 15, 2015

Copyright: ( $) 2015$, Ayakannu T et al. This is an open-access article distributed under the terms of the Creative Commons Attribution License, which permits unrestricted use, distribution, and reproduction in any medium, provided the original author and source are credited.

\begin{abstract}
Background: Although tamoxifen has well documented oestrogen-like effects in the endometrium and ectocervical squamous epithelium, its effects on the endocervix are poorly documented.

Case report: We report a case of an 88 year-old woman who presented with postmenopausal bleeding after receiving tamoxifen for 16 months following a diagnosis of Grade 2 invasive and in situ carcinoma of breast. Endometrial biopsy was performed revealing either atypical hyperplasia or adenocarcinoma. She underwent total abdominal hysterectomy, bilateral salpingo-oophorectomy and lymph gland sampling. Histopathological examination of the uterus showed an endometrioid carcinoma (FIGO Grade 2) at the endometrium. In addition, there was extensive florid endocervical microglandular hyperplasia.
\end{abstract}

Conclusion: Endocervical microglandular hyperplasia is usually seen in woman of reproductive age, particularly in association with pregnancy and contraceptive use. It is unusual in postmenopausal woman and its presence in this 88 year-old tamoxifentreated patient implicates tamoxifen as a course of endocervical microglandular hyperplasia in this instance.

Keywords: Cervical cancer; Case report; Tamoxifen; Histological daignosis

\section{Introduction}

The non-steroidal triphenylethylene derivative tamoxifen has been widely used in the management of established breast cancer [1]. Women treated with tamoxifen are at increased risk of endometrial cancer, hyperplasia and polyps [2].

\section{Case Report}

An 88 year-old Caucasian woman, gravida 2, presenting for a routine change of shelf pessary. She complained of one episode of postmenopausal bleeding. Breast biopsy and mammogram were performed in May 2002 to investigate a breast lump. All the results confirmed evidence of malignancy and resulted in left radical mastectomy and axillary node clearance to level III. Histology results revealed grade II invasive ductal carcinoma with an in situ component. There was also associated invasive lobular carcinoma of a similar grade. Thirteen lymph nodes were identified with no involvement (Grade II, T1NoMo, ER+ PR-). Postoperative hormonal therapy with tamoxifen (20 mg once daily) was administered until January 2004 and changed to Arimidex, and a five year course recommended.
The first episode of postmenopausal bleeding was 16 months after commencing on tamoxifen. The patient had an urgent ultrasound scan and endometrial biopsy. Ultrasound of the pelvis revealed an enlarged uterus with a large fibroid occupying the body and a fundus endometrium could not be separately identified. Some calcific change was also noted. Pipelle endometrial biopsy revealed scanty fragments of endometrium, showing some rather worrying features of atypical hyperplasia or adenocarcinoma. The patient underwent a total abdominal hysterectomy, bilateral salpingo-oophorectomy and lymph gland sampling together with a burch colposuspension. The patient is currently alive and symptom free.

\section{Pathological Findings}

The uterus was bulky, weighing $292 \mathrm{~g}$ and measuring $114 \times 75 \times 60$ $\mathrm{mm}$. Macroscopically, the tubes and ovaries were normal. On section, the bulky appearance was due to the presence of a $55 \times 55 \times 60 \mathrm{~mm}$ diameter fibroid in the fundus. The endometrial cavity was displaced laterally. Below the fibroid, the endometrium was $15 \mathrm{~mm}$ thick with a very irregular posterior surface. No obvious myometrial thickening was seen. The endocervical lining was smoother, but also polypoid.

Microscopic examination showed a FIGO grade 2 adenocarcinoma of the endometrium with significant myometrial invasion confined to the inner half of the uterine wall. There was no vascular invasion. The endocervix showed a florid glandular proliferation with weakened 
architecture and osmolalities. These findings caused diagnostic difficulties and the case was referred for expert opinion. The ectocervical squamous epithelium was extensively glycogenated and there was florid proliferation of tightly packed endocervical glands lined by cuboidal cells, associated with squamous metaplasia and occasionally lined by flattened endocervical cells. Mitotic figures were scanty. The stroma also shows infiltration by acute and chronic inflammatory cells. These features are those of microglandular endocervical hyperplasia as shown in Figure 1.

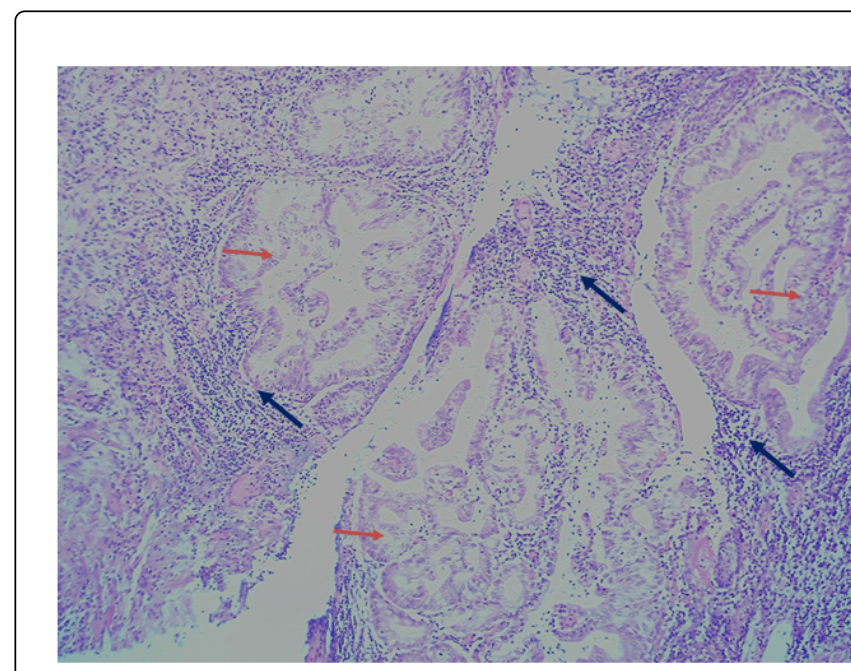

Figure 1: A photomicrograph of a haematoxylin and eosin-stained section through the endocervix of the 88-year old woman treated with tamoxifen, showing typical histopathologic features of florid endocervical microglandular hyperplasia. Note the florid tightly packed endocervical glands lined by cuboidal cells associated with squamous metaplasia (red arrows). The stroma also shows infiltration by acute and chronic inflammatory cells close to the glands (blues arrows). Image was taken at 100x magnification.

\section{Discussion}

Tamoxifen is a very useful agent for adjuvant therapy of patients with breast cancer, prolonging overall survival [3]. It works by competing with and blocking access of natural oestrogens to oestrogen receptors in the breast. However, tamoxifen also stimulates other tissues including the lower genital tract, and its long-term use is associated with an increased risk of developing endometrial polyps, hyperplasia and malignant neoplasms, with a significantly greater risk of uterine cancer has been demonstrated in patients taking tamoxifen for more than 5 years [4]. Although tamoxifen has well documented oestrogen-like effects on ectocervix squamous epithelium, its effects, if any, on the endocervix are poorly documented [5]. Oral contraceptives, pregnancy and hormone-replacement therapy are linked to the incidence of the lesion suggesting that both oestrogen and progestagen have a role to play in the pathogenesis of this condition, with $3 \%$ of oral contraceptive users destined to develop microglandular hyperplasia [6-8]. Microglandular hyperplasia of the endocervix is a localized non-neoplastic proliferation of the glandular epithelium of the endocervix. Although these growths may show architectural or cytological abnormalities, they differ from malignant tumours, and can easily be misinterpreted as pre-malignant or malignant neoplasms of the endocervix [9-11]. Microglandular hyperplasia is found most commonly in younger women (between the ages of 25-37) and is often an incidental microscopic finding [12,13], is just like adenocarcinoma of the endometrium, associated with endogenous hormones, and induced by pregnancy hormones, gynecological therapeutic treatments or through oral contraceptive therapy $[6,7,14]$. Although there are reports of endocervical microglandular hyperplasia in post-menopausal women without a history of hormone replacement, these are far rarer [8]. Our case describes an incidence of endocervical microglandular hyperplasia and adenocarcinoma in an 88 year-old tamoxifen/aromatase inhibited woman, and raises the question of association between tamoxifen and this unusual occurrence. The data thus suggest that tamoxifen is a contributory factor in microglandular hyperplasia in this older age group, and that we may see more cases of endocervical hyperplasia with adenocarcinoma in the future. Diagnosing microglandular hyperplasia of the endocervix is often difficult especially when a differential diagnosis with adenocarcinoma is necessary [15] although recent immunohistochemical approaches are showing some promise [14].

\section{Conclusion}

Published reports regarding the short-term pathological effects of tamoxifen on the endometrium are difficult to evaluate critically because of an unfortunate lack of attention to pathological detail and lack of understanding of the pathological terminology [16]. Tamoxifen may cause florid endocervical hyperplasia in older postmenopausal women, a finding which may lead to diagnostic difficulties when seen in association with endometrial carcinoma [15].

\section{References}

1. Noguchi M, Rose DP, Miyazaki I (1996) Breast cancer chemoprevention: clinical trials and research. Oncology 53: 175-181.

2. Assikis VJ, Neven P, Jordan VC, Vergote I (1996) A realistic clinical perspective of tamoxifen and endometrial carcinogenesis. Eur J Cancer 32A: 1464-1476.

3. No authors listed (1988) Effects of adjuvant tamoxifen and of cytotoxic therapy on mortality in early breast cancer. An overview of 61 randomized trials among 28,896 women. Early Breast Cancer Trialists' Collaborative Group. N Engl J Med 319: 1681-1692.

4. Fornander T, Rutqvist LE, Cedermark B, Glas U, Mattsson A, et al. (1989) Adjuvant tamoxifen in early breast cancer: occurrence of new primary cancers. Lancet 1: 117-120.

5. Khong TY, Ismail SM (2005) Handbook of endometrial pathology. Taylor and Francis, London and New York.

6. Taylor HB, Irey NS, Norris HJ (1967) Atypical endocervical hyperplasia in women taking oral contraceptives. JAMA 202: 637-639.

7. Wilkinson E, Dufour DR (1976) Pathogenesis of microglandular hyperplasia of the cervix uteri. Obstet Gynecol 47: 189-195.

8. Greeley C, Schroeder S, Silverberg SG (1995) Microglandular hyperplasia of the cervix: a true "pill" lesion? Int J Gynecol Pathol 14: 50-54.

9. Cina SJ, Richardson MS, Austin RM, Kurman RJ (1997) Immunohistochemical staining for Ki-67 antigen, carcinoembryonic antigen, and p53 in the differential diagnosis of glandular lesions of the cervix. Mod Pathol 10: 176-180.

10. Abi-Raad R, Alomari A, Hui P, Buza N (2014) Mitotically active microglandular hyperplasia of the cervix: a case series with implications for the differential diagnosis. Int J Gynecol Pathol 33: 524-530.

11. Loureiro J, Oliva E (2014) The spectrum of cervical glandular neoplasia and issues in differential diagnosis. Arch Pathol Lab Med 138: 453-483. 
Citation: $\quad$ Ayakannu T, Hew WSR, Brown L, Ismail S, Maulik TG, et al. (2015) Florid Endocervical Microglandular Hyperplasia in Association with Tamoxifen Treatment. J Cytol Histol 6: 375. doi:10.4172/2157-7099.1000375

Page 3 of 3

12. Chumas JC, Nelson B, Mann WJ, Chalas E, Kaplan CG (1985) Microglandular hyperplasia of the uterine cervix. Obstet Gynecol 66: 406-409.

13. McCluggage WG, Tidy J, Smith J (2014) Cellular pathology of glandular lesions and uncommon neoplasms of the cervix. Springer, London and Heidelberg.

14. Stewart CJ, Crook ML (2015) PAX2 and cyclin D1 expression in the distinction between cervical microglandular hyperplasia and endometrial microglandular-like carcinoma: a comparison with p16, vimentin, and Ki67. Int J Gynecol Pathol 34: 90-100.

15. Padrao IL, Andrade LALDA (2006) Microglandular hyperplasia of the cervix: frequency in cone specimens, histological patterns, clinical aspects and immunohistochemical markers for differential diagnosis with adenocarcinoma. J Bras Patol Med Lab 42: 219-225.

16. Medeiros F, Bell DA (2010) Pseudoneoplastic lesions of the female genital tract. Arch Pathol Lab Med 134: 393-403. 